\title{
Multiple protein phylogenies show that Oxyrrhis marina and Perkinsus marinus are early branches of the dinoflagellate lineage
}

\author{
Juan F. Saldarriaga, Michelle L. McEwan, Naomi M. Fast, F. J. R. Taylor \\ and Patrick J. Keeling
}

Correspondence

Juan F. Saldarriaga

jsalda@mail.botany.ubc.ca
Department of Botany, University of British Columbia, 6270 University Boulevard, Vancouver, BC, Canada V6T 1 Z4

\section{INTRODUCTION}

The alveolates are a large and diverse assemblage of protists that include three major lineages: ciliates, dinoflagellates and apicomplexans. In addition to these three well-defined and relatively well-studied groups, there are also a number of species that display alveolate features (for example cortical alveoli, i.e. membranous sacs subtending the plasma membrane), but lack features that would ally them specifically with any one of the three subgroups. These organisms, called 'Protalveolata' by Cavalier-Smith (1998), are very likely to be paraphyletic or perhaps even polyphyletic, but we use the term protalveolates in a colloquial

Published online ahead of print on 9 August 2002 as DOI 10.1099/ ijs.0.02328-0.

Abbreviation: SSU, small-subunit.

The GenBank/EMBL/DDBJ accession number for the SSU rRNA sequence of Oxyrrhis marina CCCM 534 is AF482425. The accession numbers for the actin, $\alpha$-tubulin and $\beta$-tubulin gene sequences obtained in this study are AF482399-AF482424, as outlined in Table 1. sense to simplify referring to this collection of organisms. Protalveolates are often regarded as intermediates between the major alveolate groups and are therefore potentially instrumental in reconstructing the evolutionary origin and history of the characteristics that define ciliates, dinoflagellates and apicomplexans. Here, we have examined the phylogenetic position of two such organisms, Oxyrrhis marina Dujardin 1841 and Perkinsus marinus (Mackin, Owen and Collier 1950) Levine 1978.

Oxyrrhis marina is a heterotrophic flagellate commonly found in marine and brackish near-shore waters, including rock pools, estuaries and marshes. The species has often been regarded as a dinoflagellate (e.g. Kofoid \& Swezy, 1921; Dodge, 1984; Sournia, 1986), but has also been explicitly excluded from the group in other classification schemes (Fensome et al., 1993), as it has a number of characters that are very different from those of true dinoflagellates. In Oxyrrhis, the mitotic spindle is intranuclear and originates from numerous plaques on the nuclear envelope (Triemer, 1982; Gao \& Li, 1986); in dinoflagellates, the spindle is 
extranuclear and its microtubules are located within cytoplasmic channels that traverse the nucleus (Leadbeater \& Dodge, 1967; Kubai \& Ris, 1969; Ris \& Kubai, 1974). The nuclear organization in Oxyrrhis is very atypical: it contains a large number of long, thin chromosomes, separated by numerous electron-dense bodies that could be small chromosome fragments (Dodge \& Crawford, 1971). This organization is very different from the thick, continuously condensed, fibrillar chromosomes in the dinokaryon of typical dinoflagellates. Other differences between Oxyrrhis and true dinoflagellates are the lack of a girdle, a sulcus or pusules in Oxyrrhis (some dinoflagellates have secondarily lost the girdle and/or sulcus; Fensome et al., 1993) and the presence of what could be histone proteins (Kato et al., 1997); histones are absent in the nuclei of most dinoflagellates (the order Syndiniales could be an exception: Ris \& Kubai, 1974; Sala-Rovira et al., 1991).

Perkinsus marinus is the causative agent of 'dermo', an important disease of oysters and probably many other species of bivalves (Perkins, 1976). The taxonomic placement of Perkinsus has always been problematic: over the years, the genus has been considered to be a member of the fungi, labyrinthulids and haplosporidians. Eventually, ultrastructural data led to the conclusion that Perkinsus represents an early lineage of the apicomplexans (Levine, 1978; Perkins, 1996). This conclusion was based largely on the fact that its flagellated stage contains an apical organelle with similarities to the apicomplexan conoid, an apical structure composed of microtubular units arranged in a helical coil forming a truncated cone. In Perkinsus, however, this 'conoid' is open along one side, a feature that led to a reinterpretation of the significance of the structure for the taxonomy of the genus (Siddall et al., 1997). The vegetative stage of Perkinsus marinus has, like dinoflagellates, two dissimilar flagella that insert ventrally; one of them with mastigonemes along one side (Perkins, 1996). Cell division in Perkinsus also appears to be dinoflagellatelike: the nuclear envelope remains intact during mitosis and deep channels are formed, continuous with the cytoplasm and lined by the nuclear membrane. The mitotic spindle runs through these channels and attaches to kinetochore-like structures on the nuclear envelope (Perkins, 1996). However, the interphase nuclear ultrastructure of this species is very unlike that of typical dinoflagellates: chromatin appears as electron-dense aggregates of varying density, not as the fibrillar structures of typical dinokaryons (Perkins, 1996). Most recently, Perkinsus was placed in its own alveolate phylum, the Perkinsozoa, together with a newly described parasite of dinoflagellates, Parvilucifera infectans (Norén et al., 1999).

Molecular data from the protalveolates are uncommon, but small-subunit (SSU) rRNA and actin sequences have been used to address the phylogenetic position of Perkinsus. Together, these two gene phylogenies provide fairly convincing evidence that Perkinsus is closely related to dinoflagellates, not apicomplexans (Goggin \& Barker, 1993;
Reece et al., 1997). Nevertheless, the support for this position is sometimes not very strong in SSU rRNA trees (e.g. Siddall et al., 1997), and other analyses of SSU rRNA have also shown Perkinsus and Parvilucifera branching at the base of the apicomplexans (Norén et al., 1999). In actin phylogenies, the very divergent sequences of ciliates fall far from either dinoflagellates or apicomplexans (e.g. Keeling, 2001), making it difficult to draw any firm conclusions on the position of Perkinsus based solely on this gene. The phylogenetic position of Oxyrrhis has not been substantially investigated using molecular data. Only one report describes any sequence data from Oxyrrhis (Lenaers et al., 1991), and here only 235 nucleotides from two domains of the large subunit rRNA gene were used: phylogenetic trees inferred from this sequence and that of 12 dinoflagellates and one ciliate placed Oxyrrhis basal to the dinoflagellates (no apicomplexan sequences were included). Recently, SSU rRNA sequences from a number of unidentified alveolates were obtained from environmental samples of marine picoplankton (López-García et al., 2001; Moon-van der Staay et al., 2001; Diez et al., 2001) and one large group of sequences was proposed to be from relatives of Oxyrrhis (Moon-van der Staay et al., 2001). This hypothesis has not been tested, as no SSU rRNA sequence for Oxyrrhis has been available.

To investigate the origins of Oxyrrhis and Perkinsus further, we have sequenced genes encoding SSU rRNA, actin, $\alpha$-tubulin and $\beta$-tubulin from Oxyrrhis marina, $\alpha$-tubulin and $\beta$-tubulin from Perkinsus marinus and actin, $\alpha$-tubulin and $\beta$-tubulin from a variety of dinoflagellates. We inferred phylogenies of these genes individually and in combination to determine the relationships between Oxyrrhis, Perkinsus and other alveolates and to begin to reconstruct the nature of the ancestors of dinoflagellates and apicomplexans.

\section{METHODS}

Cultures of Oxyrrhis marina and all photosynthetic dinoflagellates examined were obtained from culture collections as listed in Table 1. Marine cultures were maintained in HESNW medium (Harrison et al., 1980), while fresh-water organisms (Peridinium willei and Woloszynskia tenuissima; nomenclature as in Popovský \& Pfiester, 1990) were cultured as recommended by NIES. Genomic DNA from Perkinsus marinus was a gift from R. Waller and G. McFadden (Melbourne, Australia). A second SSU rRNA sequence from a different isolate of Oxyrrhis marina (NIES 494) was recently released to GenBank (accession no. AB033717; K. Takishita, K. Aoi and A. Uchida, unpublished) and was also included in our analyses.

DNA was purified from all cultures using the Plant DNeasy kit (Qiagen). The SSU rRNA gene of Oxyrrhis marina was amplified using two sets of primers resulting in overlapping fragments. The $3^{\prime}$ end of the gene was obtained with primers designed to amplify all eukaryotic SSU rRNA genes (5'-CCGGATCCTGATCCTTCTGCAGGTTCACCTAC and 5'-GCGGTAATTCCAGCT). The remainder of the $5^{\prime}$ end of the gene was amplified using another eukaryotespecific primer (5'-CGAATTCAACCTGGTTGATCCTGCCAGT) and a primer designed to recognize only dinoflagellate SSU rRNA sequences (5'-ACTTACTCTTTTCAGGCAC). Protein-coding genes for all organisms except Perkinsus marinus were amplified using the 
Table 1. Accession numbers for the new protein-coding gene sequences

\begin{tabular}{|lccc|}
\hline Taxon & Actin & $\boldsymbol{\alpha}$-Tubulin & $\boldsymbol{\beta}$-Tubulin \\
\hline Amphidinium corpulentum UTEX LB1562 & - & - & AF482405 \\
Amphidinium herdmanii CCCM D532 & - & AF482406, AF482407 & - \\
Gyrodinium instriatum CCMP 431 & - & - & AF482408 \\
Heterocapsa rotundata CCCM D680 & AF482409 & AF482410 & - \\
Heterocapsa triquetra CCMP 449 & AF482411 & AF482412 & AF482413, AF482414 \\
Karenia brevis CCMP 718 & AF482415-AF482418 & AF482419 & - \\
Oxyrrhis marina CCCM 534 & AF482402 & AF482403 & AF482404 \\
Peridinium willei NIES 304 & AF482420 & - & AF482421 \\
Perkinsus marinus $\dagger$ & - & AF482399, AF482400 & AF482401 \\
Symbiodinium sp. CCMP 421 & AF482423 & - & AF482424 \\
Woloszynskia tenuissima NIES 619 & - & - & AF482422 \\
\hline
\end{tabular}

*The accession number for the SSU rRNA sequence of Oxyrrhis marina CCCM 534 is AF482425.

tDNA was kindly provided by R. Waller and G. McFadden. Actin sequence data were taken from Reece et al. (1997).

following primers: 5'-GAGAAGATGACNCARATHATGTTYGA and 5'-GGCCTGGAARCAYTTNCGRTGNAC for actin, 5' -TCCGAATTCARGTNGGNAAYGCNGGYTGGGA and 5' -CGCGCCATNCCYTCNCCNACRTACCA for $\alpha$-tubulin and $5^{\prime}$-GCCTGCAGGNCARTGYGGNAAYCA and 5'-TCCTCGAGTRAAYTCCATYTCRTCCAT for $\beta$-tubulin, all in PCRs using genomic DNA. $\alpha$-Tubulin and $\beta$-tubulin were amplified from Perkinsus marinus DNA using a two-step nested PCR approach, since only small quantities of DNA were available. The initial $10 \mu \mathrm{l}$ reaction used primers $5^{\prime}$-GGGCCCCAGGTCGGCAAYGCNTGYTGG and 5'-GGGCCCCGAGAACTCSCCYTCYTCCAT for $\alpha$-tubulin and $5^{\prime}$-GCCTGCAGGNCARTGYGGNAAYCA and $5^{\prime}$-TCCTCGAGTRAAYTCCATYTCRTCCAT for $\beta$-tubulin. These reactions were used to seed a second $50 \mu \mathrm{l}$ reaction using primers 5 '-TCCGAATTCARGTNGGNAAYGCNGGYTGGGA and 5' -CGCGCCATNCCYTCNCCNACRTACCA for $\alpha$-tubulin and $5^{\prime}$-CAGATCGGCGCGAARTTYTGGGARAT and 5'-CTCGTCCATGCCYTCNCCNGTRTACCA for $\beta$-tubulin. Sequences from Heterocapsa triquetra were obtained by RT-PCR. Total RNA was isolated with the RNeasy kit (Qiagen) and poly(A) ${ }^{+}$RNA was isolated with the Oligotex mRNA kit (Qiagen). Full-length RNAs were selected following the procedure of Suzuki et al. (1997) and Maruyama \& Sugano (1994) and cDNA was synthesized with a poly $(\mathrm{dT})$ primer using standard methods. An amplified cDNA pool served as template for degenerate PCRs using the primers described above.

PCR products were cloned into vector pCR 2.1 using the TOPO TA cloning kit (Invitrogen) and several clones of each gene were sequenced on both strands. Protein-coding gene sequences were translated and added to existing alignments of eukaryotic sequences (Van de Peer et al., 1998; Saldarriaga et al., 2001; Keeling, 2001; Fast et al., 2002). Only unambiguously aligned characters were used in the phylogenetic analyses, resulting in respective datasets of 1488, 244, 384 and 395 characters for SSU, actin, $\alpha$-tubulin and $\beta$-tubulin. Phylogenetic trees were inferred both by using comprehensive alignments containing a large number of taxonomically diverse eukaryotes to confirm the alveolate nature of the Oxyrrhis and Perkinsus sequences and also with smaller subsets of these alignments that contain only alveolate taxa, so that more sophisticated analyses could be performed. In SSU rRNA trees, Perkinsus was used alone to represent all perkinsids, since the sequence from Parvilucifera is comparatively very divergent. In the larger, global analyses, Oxyrrhis and Perkinsus sequences were always related most closely to apicomplexans and dinoflagellates so, for most of the smaller datasets, ciliates were used as the outgroup. This was not the case in the actin dataset: ciliate actin sequences are known to be so divergent that they do not form a group with other alveolates (e.g. Keeling, 2001). In this case, heterokonts were used as outgroups, as these seem to be the nearest relatives to alveolates in actin phylogenies (e.g. Baldauf et al., 2000; Keeling, 2001). In addition to the single-gene datasets, an alignment composed of concatenated sequences of actin, $\alpha$-tubulin and $\beta$-tubulin was also produced (1023 amino acids). It contained only alveolate taxa for which the complete sequence of all three genes is known: three ciliates, three apicomplexans, Oxyrrhis, Perkinsus and the only dinoflagellate for which we could obtain all three genes, Heterocapsa triquetra.

Phylogenies from the single-gene and the concatenated datasets were inferred using distance and maximum-likelihood methods of tree reconstruction. Distance matrices were calculated with TREE-PUZZLE 5.0 (Strimmer \& Von Haeseler, 1996) using the HKY substitution frequency matrix for nucleotides and the WAG substitution matrix for proteins. Nucleotide and amino acid frequencies, as well as transition/ transversion ratios in the case of SSU, were estimated from the data. The among-site rate variation was modelled on a $\Gamma$ distribution with invariable sites plus eight variable rate categories, and the $\alpha$ shape parameter was estimated from the data. Distance trees were constructed using weighted neighbour-joining using WEIGHBOR (Bruno et al., 2000) and Fitch-Margoliash using FITCH (Felsenstein, 1993). One hundred bootstrap datasets were constructed using SEQBOOT and distances were calculated using PUZZLEBOOT (by M. Holder and A. Roger; http:// www.tree-puzzle.de) with the $\alpha$ shape parameter, nucleotide or amino acid frequencies and transition/transversion ratio from the initial tree enforced on the 100 replicates. Protein maximum-likelihood trees were inferred using ProML (Felsenstein, 1993) with the JTT substitution frequency matrix, global rearrangements and 10 input-order jumbles. Site-to-site rate variation was modelled using the $r$ option with the frequencies and rates calculated by TREE-PUZZLE. Protein maximumlikelihood bootstrapping was performed as above, with the rates and rate categories from the original dataset enforced on each replicate. Because of computational limitations, a dataset restricted to 30 species and 1581 nucleotides was used to infer maximum-likelihood trees of SSU rRNA sequences. These trees were inferred under an HKY model incorporating a discrete $\Gamma$ distribution to correct for rate heterogeneity (invariable sites and eight variable rate categories, the shape parameter, nucleotide frequencies and transition/transversion ratio were estimated from the data, 10 input-order jumbles) using PAUP $4.0 \mathrm{~b} 8$ (Swofford, 1999). 


\section{RESULTS AND DISCUSSION}

\section{SSU rRNA phylogeny of Oxyrrhis, Perkinsus and Colpodella}

The taxonomic diversity of known alveolate SSU rRNA genes is quite broad, but data from Oxyrrhis marina were lacking, so as a first step in characterizing its phylogenetic position we amplified and sequenced the SSU rRNA gene from that species. The SSU rRNA sequence of Oxyrrhis proved to be extremely divergent, as can be seen in inferred trees (Fig. 1). In all phylogenetic analyses, the two Oxyrrhis isolates branched together with very high support (the two sequences are very similar). In analyses including all eukaryotes (Fig. 1), and in a more detailed analysis restricted to alveolates only (not shown), Oxyrrhis nearly always branched with the dinoflagellate order Gonyaulacales, and this relationship was generally relatively well supported by bootstrap (e.g. 81 and $76 \%$ support uniting Oxyrrhis and the gonyaulacalean Gonyaulax spinifera in Fig. 1). The only analysis where this relationship did not appear was the maximum-likelihood tree of alveolatesonly, where Oxyrrhis branches from within the dinoflagellates, but not specifically with Gonyaulacales (not shown). However, the divergent nature of the Oxyrrhis sequences makes it difficult to draw any firm conclusions about the phylogenetic placement of the species. Indeed, the Oxyrrhis branch lengths in the weighted neighbour-joining distance tree of Fig. 1, for example, are almost eight times as long as that of Gonyaulax spinifera. Accordingly, the SSU rRNA phylogeny must be considered very cautiously, especially as Oxyrrhis tends to branch with the Gonyaulacales, an otherwise morphologically coherent group with relatively divergent SSU rRNA sequences compared with other dinoflagellates (Saunders et al., 1997; Saldarriaga et al., 2001). Both the large eukaryotic dataset (Fig. 1) and the alveolateonly dataset (not shown) contained sequences from the unidentified group of marine alveolates proposed to be related to Oxyrrhis (Moon-van der Staay et al., 2001), but in no tree did the Oxyrrhis sequence branch with that group. Although the divergent nature of the Oxyrrhis sequence makes any conclusions difficult, this analysis obviously does not support the notion that these unidentified organisms are closely related to Oxyrrhis. Nevertheless, as shown below, the position of Oxyrrhis in SSU rRNA phylogenies is likely false; its true position is at the base of the dinoflagellates. Accordingly, a possible relationship between Oxyrrhis and these picoplanktonic alveolates cannot be excluded.

The position of Perkinsus in the SSU rRNA analysis (basal to dinoflagellates) is consistent with most results published previously (Goggin \& Barker, 1993; Siddall et al., 1997). However, this position is not well supported by bootstrap (e.g. 58 and $<50 \%$ in Fig. 1), and other analyses of SSU rRNA have found conflicting positions for Perkinsus and the related Parvilucifera (Norén et al., 1999). The combination of poor bootstrap support and conflicting results indicates that SSU rRNA data are insufficient to resolve the position of perkinsids and other data must be sought. It is also noteworthy that the SSU rRNA sequence from Colpodella, another protalveolate unrelated to Perkinsus or Oxyrrhis, branches at the base of the apicomplexans, as previously seen in analyses based on SSU rRNA (Siddall et al., 2001; Leander et al., 2003).

\section{Phylogenetic position of Oxyrrhis and Perkinsus based on actin, $\alpha$-tubulin and $\beta$-tubulin sequences}

Given the difficulties imposed by the divergent Oxyrrhis SSU rRNA sequence and the general lack of support for the topology of the SSU rRNA tree of dinoflagellates, we sought to examine the relationships between Oxyrrhis, Perkinsus, dinoflagellates and apicomplexans using three proteincoding genes: actin, $\alpha$-tubulin and $\beta$-tubulin. Genes encoding all three proteins were amplified from Oxyrrhis and both $\alpha$-tubulin and $\beta$-tubulin were amplified from Perkinsus. As no $\alpha$-tubulin sequences and only three actin and one $\beta$-tubulin sequences have previously been characterized from dinoflagellates, we amplified those three genes from several members of the group (actin from five species, $\alpha$-tubulin from four and $\beta$-tubulin from seven species; summarized in Table 1). In many species of dinoflagellates, we found more than one copy of a particular gene. For example, we sequenced two different copies of $\alpha$-tubulin from Amphidinium herdmanii, two $\beta$-tubulin genes from both Heterocapsa triquetra and Perkinsus marinus and four distinct actin genes from Karenia brevis. We also found introns in two genes: one in the $\alpha$-tubulin gene from Heterocapsa rotundata (107 bp) and one in the $\beta$-tubulin gene of Symbiodinium sp. CCMP 421 (120 bp).

In contrast to the SSU rRNA gene, none of the three proteincoding genes sampled from Oxyrrhis was found to be particularly divergent (neither were the new tubulin genes from Perkinsus). All of the large, taxonomically diverse phylogenetic trees based on actin (Fig. 2), $\alpha$-tubulin (Fig. 3) and $\beta$-tubulin (Fig. 4) place both Oxyrrhis and Perkinsus within the alveolate clade, confirming their general taxonomic position as alveolates. However, unlike the SSU rRNA trees, the protein trees almost never show Oxyrrhis branching within the dinoflagellates: in the weighted neighbour-joining tree of actin (Fig. 2), the dinoflagellate Crypthecodinium cohnii branches below an Oxyrrhis/ Perkinsus clade (without bootstrap support), but both maximum-likelihood and distance trees based on only alveolate sequences from all three proteins (Fig. 5a-c) place Oxyrrhis and Perkinsus earlier than all dinoflagellates. In general, actin phylogenies (Figs 2 and 5a) produce consistent and strong support for both Oxyrrhis and Perkinsus branching with the dinoflagellates, but little or no support for the node uniting dinoflagellates at the exclusion of Oxyrrhis and Perkinsus. We must also note that the actin sequence reported from Colpodella (Siddall et al., 2001) branches at the base of the kinetoplastids in Fig. 2. This sequence was derived from a culture fed on Bodo, so this 


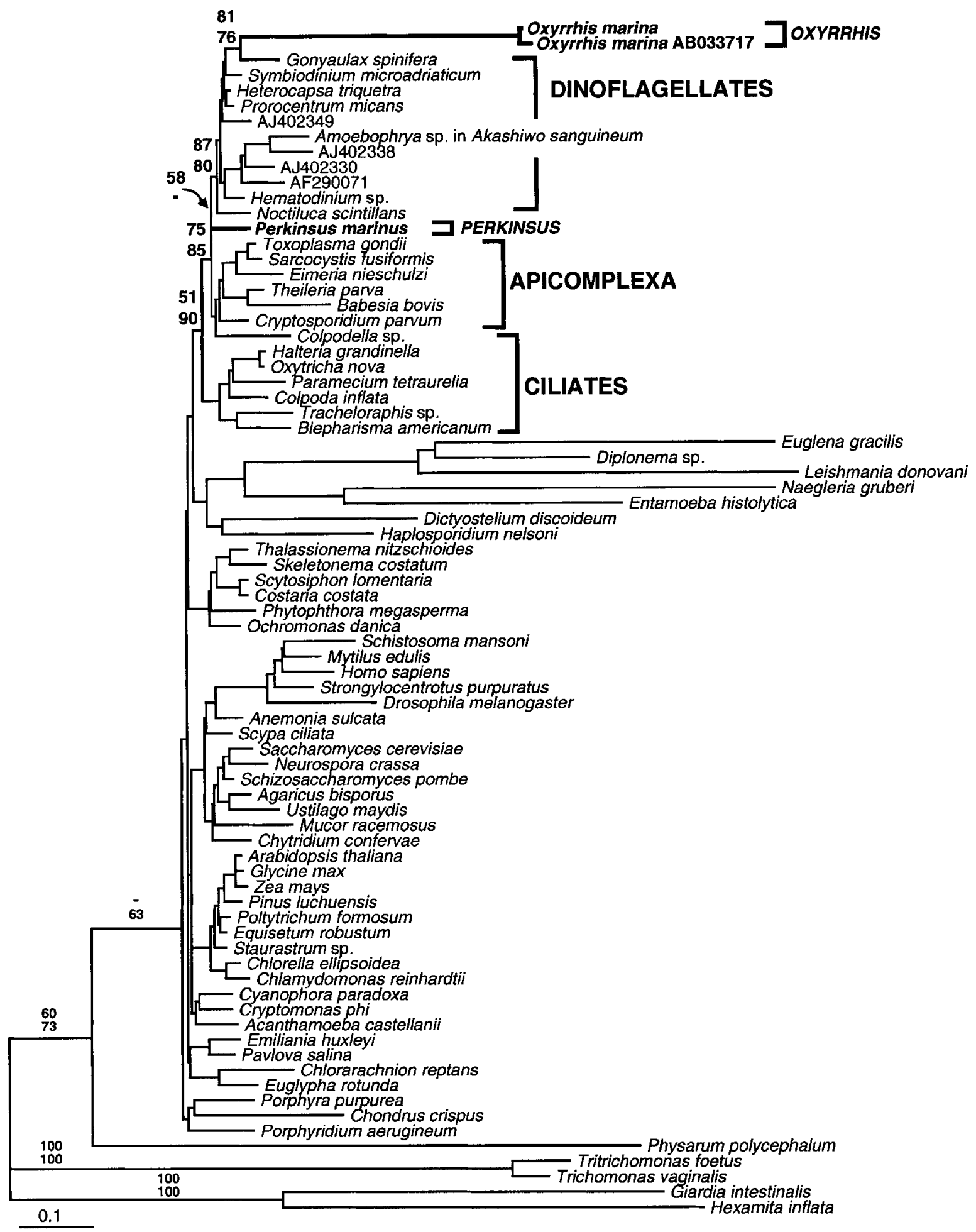

Fig. 1. Phylogenetic tree constructed with weighted neighbour-joining from a $\Gamma$-corrected distance matrix of SSU rRNA sequences (1488 nt) from 78 phylogenetically diverse eukaryotic species. Bootstrap values, based on weighted neighbourjoining (top) and Fitch-Margoliash (bottom), are shown above selected internodes. Alveolate groups are marked. Accession numbers are given for sequences from environmental samples of undetermined taxonomic identity (López-García et al., 2001; Moon-van der Stay et al., 2001) and for the Japanese isolate of Oxyrrhis marina. 


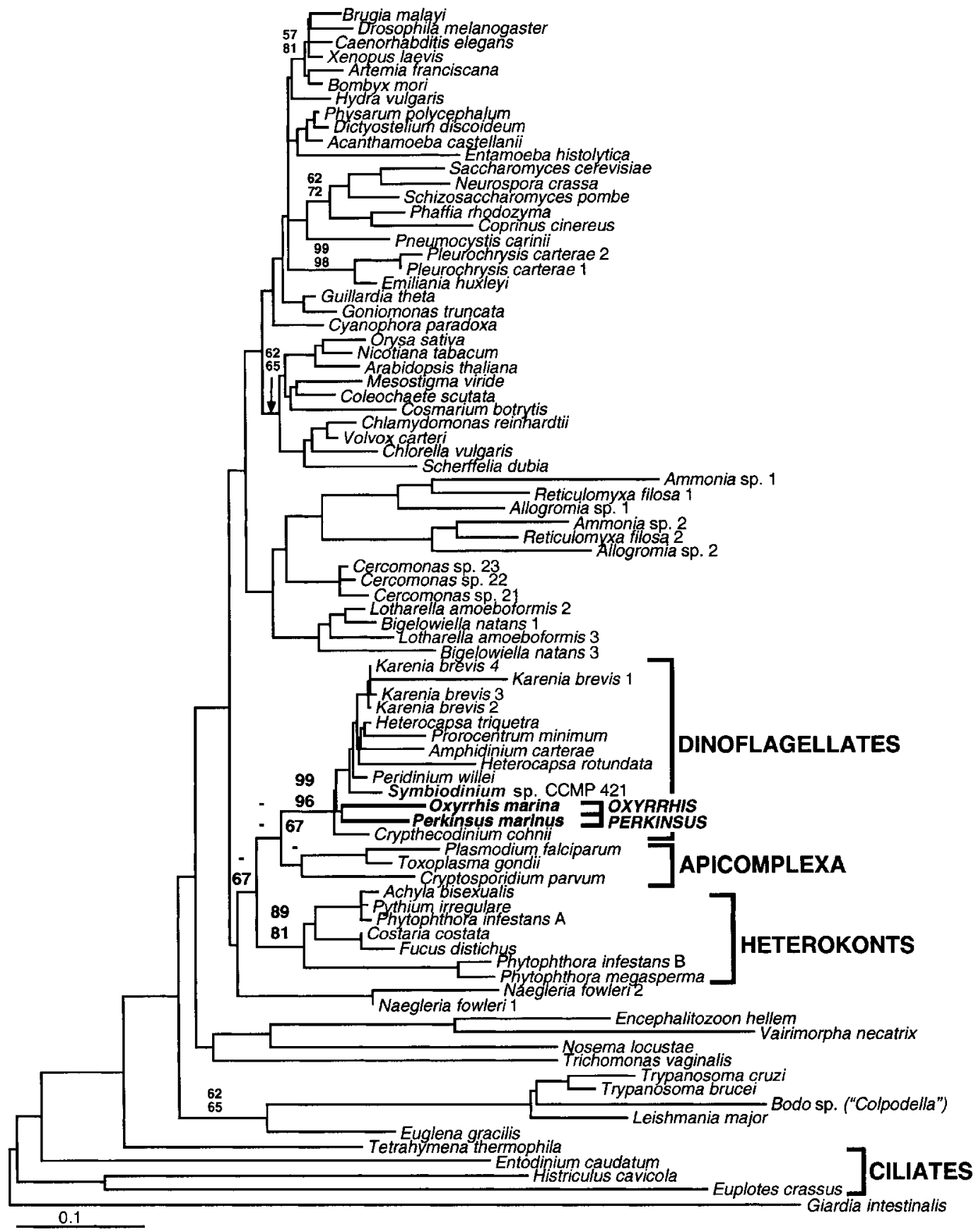

Fig. 2. Phylogenetic tree constructed with weighted neighbour-joining from a $\Gamma$-corrected distance matrix of actin sequences (244 aa) from 85 phylogenetically diverse eukaryotic species. Bootstrap values, based on weighted neighbour-joining (top) and Fitch-Margoliash (bottom), are shown above selected internodes. Alveolate groups and heterokonts are marked.

actin gene is almost certainly derived from Bodo and not from Colpodella. $\alpha$-Tubulin trees (Figs 3 and $5 b$ ) are probably the most robust of the three protein-coding genes and consistently show very high support for both Oxyrrhis and Perkinsus branching at the base of dinoflagellates. In $\beta$-tubulin phylogenies of alveolates, it has previously been shown that ciliates are paraphyletic (Fast et al., 2001), and the same is found here (Figs 4 and 5c).
Nevertheless, Oxyrrhis branches with the dinoflagellates with variable levels of support in different analyses and Perkinsus also branches at the base of the dinoflagellates in analyses restricted to alveolates (in the large weighted neighbour-joining tree, Fig. 4, it also branches at the base of dinoflagellates, but as sister to a ciliate, Stylonychia). Moreover, in all $\beta$-tubulin trees, the dinoflagellates form a very strongly supported clade to the exclusion of both 


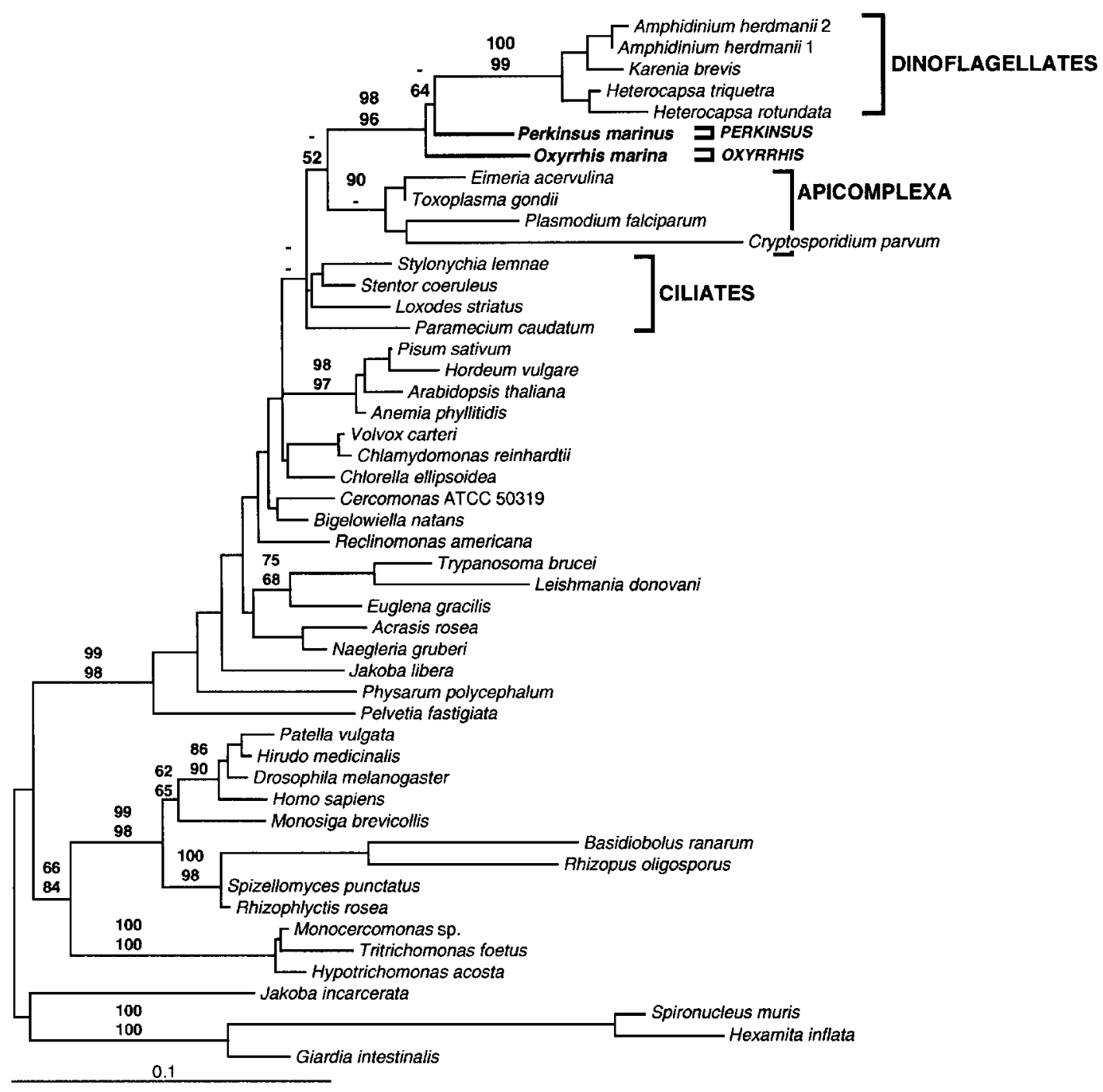

Fig. 3. Phylogenetic tree constructed with weighted neighbour-joining from a $\Gamma$-corrected distance matrix of $\alpha$-tubulin sequences (384 aa) from 50 phylogenetically diverse eukaryotic species. Bootstrap values as in Fig. 2. Alveolate groups are marked.

Perkinsus and Oxyrrhis (97-100\% bootstrap support). Lastly, in trees based on concatenated actin, $\alpha$-tubulin and $\beta$-tubulin sequences (Fig. $5 \mathrm{~d}$ ), there is very strong support for a clade containing Perkinsus, Oxyrrhis and dinoflagellates (100\% bootstrap support), but this dataset could not address whether either taxon branched within the dinoflagellates, since only one dinoflagellate was represented.

The phylogenies described above consistently support the conclusion that both Perkinsus and Oxyrrhis diverged from early ancestors of the dinoflagellates, but the order in which Perkinsus, Oxyrrhis and the true dinoflagellates branch is highly inconsistent. Among the trees, examples can be found where Oxyrrhis branches earlier than Perkinsus and the dinoflagellates (Fig. 3), where Perkinsus branches earlier than Oxyrrhis and the dinoflagellates (Fig. 5a, c) or even where Perkinsus and Oxyrrhis are sisters (Figs 2 and 5b). In cases where Perkinsus and Oxyrrhis are sisters, there is little support for the node uniting them. Similarly, there is typically little support for the node separating them in other analyses, although trees placing Perkinsus deeper tend to enjoy slightly higher bootstrap support. The concatenated dataset proved to be very useful for addressing this question, since the relative branching order of Perkinsus, Oxyrrhis and dinoflagellates could still be discerned from these trees even if only one dinoflagellate is represented. In this case (Fig. 5d), there is consistent and relatively high bootstrap support for Perkinsus branching first, followed by Oxyrrhis and the dinoflagellate, Heterocapsa. This most common branching order is most likely to be correct, but further data on this point are required. 


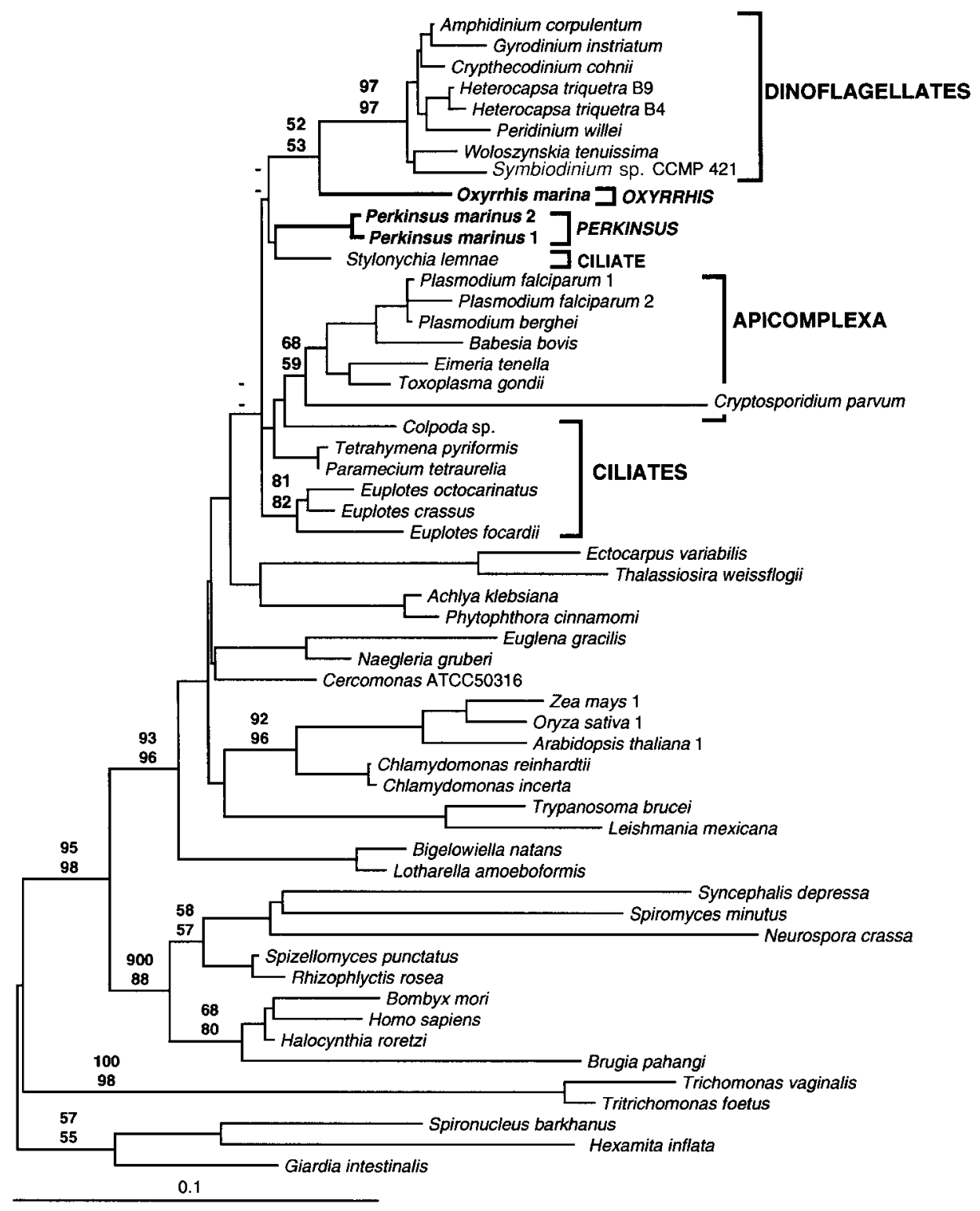

Fig. 4. Phylogenetic tree constructed with weighted neighbour-joining from a $\Gamma$-corrected distance matrix of $\beta$-tubulin sequences (395 aa) from 56 phylogenetically diverse eukaryotic species. Bootstrap values as in Fig. 2. Alveolate groups are marked.

\section{Conclusions - the early evolution of dinoflagellates and apicomplexans}

The results obtained from the SSU rRNA phylogenetic trees are not congruent with those obtained from any of the protein-gene trees: while in SSU rRNA-based trees, Oxyrrhis marina appears to have evolved from within the Gonyaulacales, in trees based on any of the three proteingenes, it branches as a sister taxon to all dinoflagellates. The highly divergent nature of the Oxyrrhis marina SSU rRNA sequences is likely causing them to branch artificially with the Gonyaulacales, since they too have divergent SSU rRNA genes compared with other dinoflagellates (e.g. Saunders et al., 1997; Saldarriaga et al., 2001). In contrast, the Oxyrrhis protein-coding gene sequences are generally no more or less derived than the dinoflagellate homologues and produce congruent phylogenetic trees that strongly support Oxyrrhis branching at the base of the dinoflagellates.

The phylogenetic position of the protalveolate Colpodella is also affected by these data. Previously, it was shown that SSU rRNA trees often placed Colpodella at the base of apicomplexans, but trees combining SSU rRNA and actin place it at the base of ciliates (Siddall et al., 2001). It seems clear, however, that the actin gene used in this study is from Bodo, not Colpodella (see Fig. 2). Combining the Colpodella SSU rRNA with the Bodo actin could have 


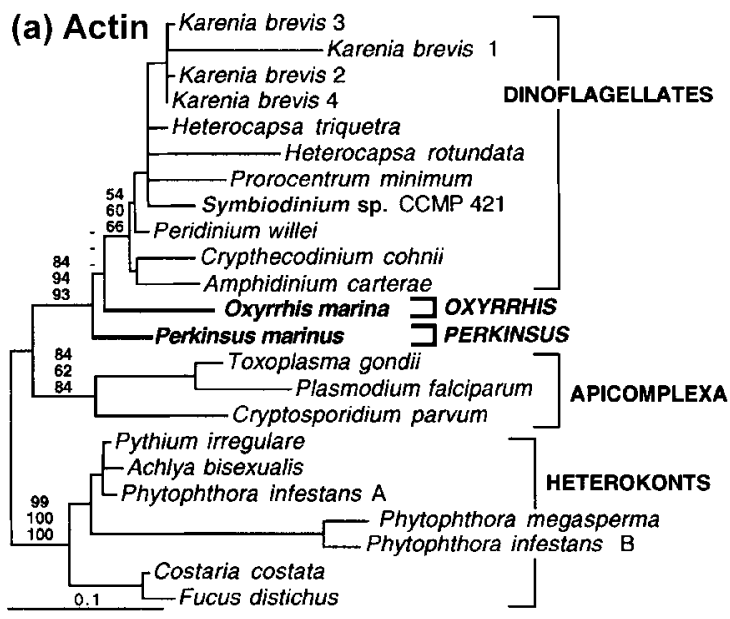

(b) $\alpha$-Tubulin
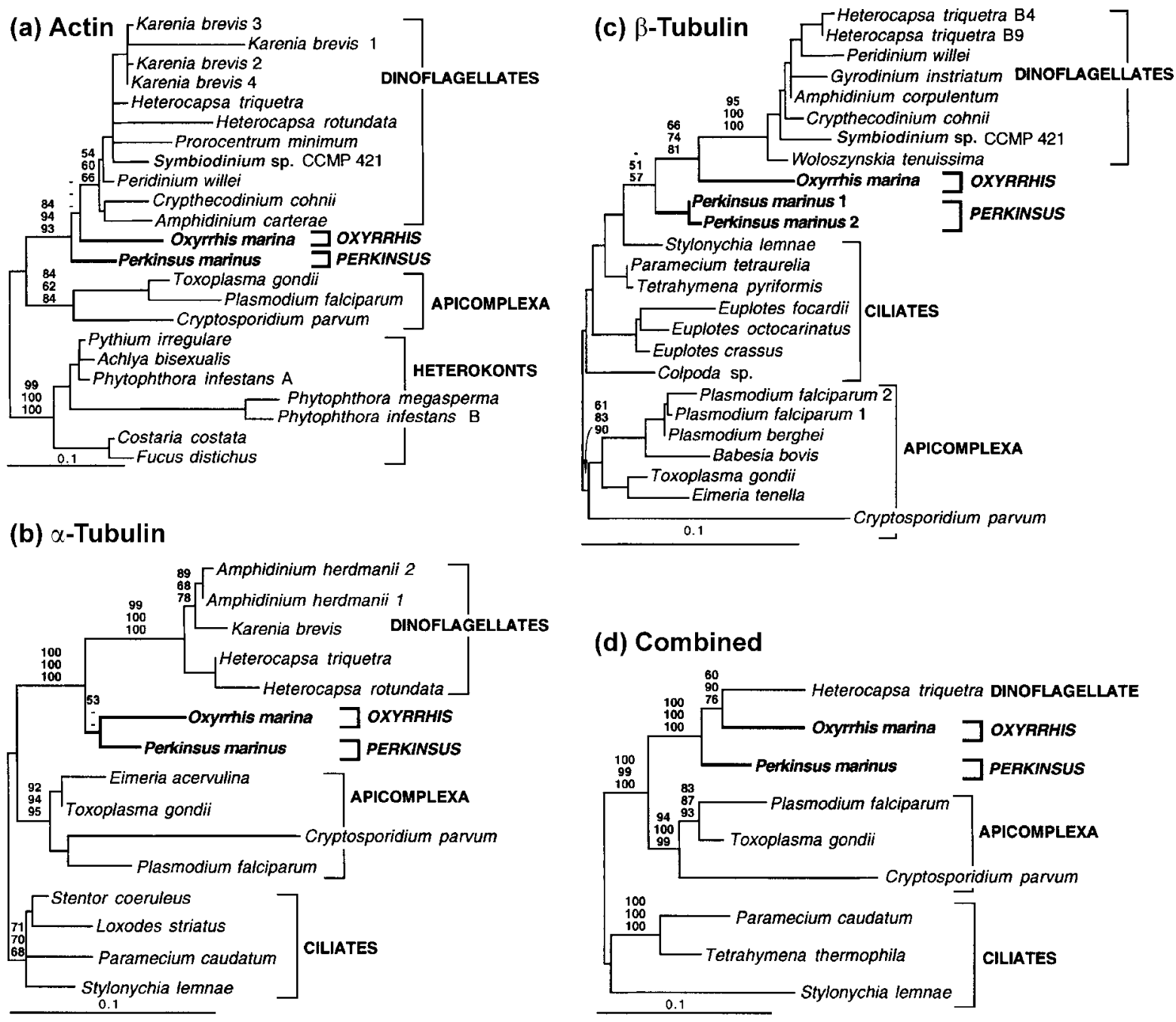

Fig. 5. $\Gamma$-Corrected protein maximum-likelihood phylogenetic trees based on actin (a), $\alpha$-tubulin (b) and $\beta$-tubulin (c) genes and a concatenated dataset of actin, $\alpha$ - and $\beta$-tubulin sequences (d) from alveolates using ciliates as an outgroup. In (a), heterokonts are included instead of ciliates (see text for explanation). Bootstrap values based on protein maximum-likelihood (top), weighted neighbour-joining (centre) and Fitch-Margoliash (bottom) are shown above selected internodes.

artificially forced 'Colpodella' to branch deeper in the alveolates in these analyses, especially since the ciliate actins are very divergent and do not branch with other alveolates in actin phylogenies (e.g. Keeling, 2001).

Determining the phylogenetic position of protalveolates like Perkinsus, Oxyrrhis and Colpodella may prove to be very useful for determining the evolutionary history of a number of morphological characters in alveolates. In the dinoflagellate lineage, for example, it now seems likely that lateral or ventral insertion of flagella originated soon after the divergence from the apicomplexan lineage, since it is a character also present in Perkinsus (Perkins, 1996) and in Oxyrrhis (Dodge \& Crawford, 1971). In Colpodella, the site of flagellar insertion varies in the different species (Simpson \& Patterson, 1996), and apicomplexans either lack flagella completely (gregarines) or have microgametes with apical flagella (e.g. coccidians; Levine, 1985). Similarly, a number of the features that characterize the dinoflagellate transverse flagellum (a feature used to define the group; Fensome et al., 1993) also seem to be present in Perkinsus and Oxyrrhis (Roberts, 1985; Perkins, 1996; Dodge \& Crawford, 1971). On the other hand, the dinokaryotic nuclei of dinoflagellates is one feature that most likely originated within the true dinoflagellates: Oxyrrhis has a nuclear organization that is significantly different from that of both dinokaryotic and syndinialean (i.e. histone-containing) dinoflagellates. It also has scales (Clarke \& Pennick, 1976), an unusual cytoskeleton (Höhfeld \& Melkonian, 1998) and a flagellar root system (Roberts, 1985, 1991) that, although reminiscent of and clearly related to those of dinoflagellates, also present important differences. Whether these differences were already present in the common ancestor of Oxyrrhis and the dinoflagellates or they arose in 
the Oxyrrhis lineage is still unclear. In the case of the apicomplexan lineage, it appears that some elements of the apical complex of apicomplexa probably originated prior to the divergence of that group from the dinoflagellate lineage. A few of these structures seem to be present in modified forms in Perkinsus (Perkins, 1996) and may well be homologous to structures surrounding the apical pore of dinoflagellates (Siddall et al., 1997).

In order to answer these kinds of questions with any certainty, more molecular and ultrastructural data are needed. By identifying the evolutionary position of the various protalveolates, we can begin to piece together the evolutionary history of some of the important characters that define the major alveolate groups. However, it is also necessary to expand the molecular phylogenetic data for some of the most poorly studied protalveolates (e.g. Colpodella, Colponema, ellobiopsids), as well as basal dinoflagellates and apicomplexans (e.g. syndinians and gregarines).

\section{ACKNOWLEDGEMENTS}

This work was supported by a grant (MOP-42517) to P. J. K. from the Canadian Institutes for Health Research (CIHR). N. M. F. is supported by Fellowships from the CIHR and the Michael Smith Foundation for Health Research (MSFHR). P. J. K. is a Scholar of the MSFHR and the Canadian Institute for Advanced Research (CIAR). We thank Brian Leander and John Archibald for critical reading of the manuscript and Ross Waller and Geoff McFadden for providing Perkinsus marinus DNA.

\section{REFERENCES}

Baldauf, S. L., Roger, A. J., Wenk-Siefert, I. \& Doolittle, W. F. (2000). A kingdom-level phylogeny of eukaryotes based on combined protein data. Science 290, 972-977.

Bruno, W. J., Socci, N. D. \& Halpern, A. L. (2000). Weighted neighbor joining: a likelihood-based approach to distance-based phylogeny reconstruction. Mol Biol Evol 17, 189-197.

Cavalier-Smith, T. (1998). A revised six-kingdom system of life. Biol Rev Camb Philos Soc 73, 203-266.

Clarke, K. J. \& Pennick, N. C. (1976). The occurrence of body scales in Oxyrrhis marina. Br Phycol J 11, 345-348.

Diez, B., Pedros-Alio, C. \& Massana, R. (2001). Study of genetic diversity of eukaryotic picoplankton in different oceanic regions by small-subunit rRNA gene cloning and sequencing. Appl Environ Microbiol 67, 2932-2941.

Dodge, J. D. (1984). Dinoflagellate taxonomy. In Dinoflagellates, pp. 17-42. Edited by D. L. Spector. Orlando: Academic Press.

Dodge, J. D. \& Crawford, R. M. (1971). Fine structure of the dinoflagellate Oxyrrhis marina. Part 2: the flagellar system. Protistologica 7, 399-409.

Fast, N. M., Kissinger, J. C., Roos, D. S. \& Keeling, P. J. (2001). Nuclear-encoded, plastid-targeted genes suggest a single common origin for apicomplexan and dinoflagellate plastids. Mol Biol Evol 18, $418-426$.
Fast, N. M., Xue, L., Bingham, S. \& Keeling, P. J. (2002). Reexamining alveolate evolution using multiple protein molecular phylogenies. J Eukaryot Microbiol 49, 30-37.

Felsenstein, J. (1993). PHYLIP (Phylogeny Inference Package). Distributed by the author. Department of Genetics, University of Washington, Seattle, USA.

Fensome, R. A., Taylor, F. J. R., Norris, G., Sarjeant, W. A. S., Wharton, D. I. \& Williams, G. L. (1993). A Classification of Living and Fossil Dinoflagellates. Micropaleontology Special Publication no. 7. New York: American Museum of Natural History.

Gao, X. P. \& Li, J. Y. (1986). Nuclear division in the marine dinoflagellate Oxyrrhis marina. J Cell Sci 85, 161-175.

Goggin, C. L. \& Barker, S. C. (1993). Phylogenetic position of the genus Perkinsus (Protista, Apicomplexa) based on small subunit ribosomal RNA. Mol Biochem Parasitol 60, 65-70.

Harrison, P. J., Waters, R. E. \& Taylor, F. J. R. (1980). A broad spectrum artificial sea water medium for coastal and open ocean phytoplankton. J Phycol 16, 28-35.

Höhfeld, I. \& Melkonian, M. (1998). Lifting the curtain? The microtubular cytoskeleton of Oxyrrhis marina (Dinophyceae) and its rearrangement during phagocytosis. Protist 149, 75-88.

Kato, K. H., Moriyama, A., Huitorel, P., Cosson, J., Cachon, M. \& Sato, H. (1997). Isolation of the major basic nuclear protein and its localization on chromosomes of the dinoflagellate, Oxyrrhis marina. Biol Cell 89, 43-52.

Keeling, P. J. (2001). Foraminifera and Cercozoa are related in actin phylogeny: two orphans find a home? Mol Biol Evol 18, 1551-1557.

Kofoid, C. A. \& Swezy, O. (1921). The Free-living Unarmored Dinoflagellata. University of California Memoirs, vol. 5. Berkeley, CA: University of California Press.

Kubai, D. F. \& Ris, H. (1969). Division in the dinoflagellate Gyrodinium cohnii (Schiller). A new type of nuclear reproduction. $J$ Cell Biol 40, 508-528.

Leadbeater, B. \& Dodge, J. D. (1967). An electron microscope study of nuclear and cell division in a dinoflagellate. Arch Mikrobiol 57, 239-254.

Leander, B. L., Clopton, R. E. \& Keeling, P. J. (2003). Phylogeny of gregarines (Apicomplexa) as inferred from small-subunit rDNA and $\beta$-tubulin. Int J Syst Evol Microbiol 53, 345-354.

Lenaers, G., Scholin, C., Bhaud, Y., Saint-Hilaire, D. \& Herzog, M. (1991). A molecular phylogeny of dinoflagellate protists (pyrrophyta) inferred from the sequence of $24 \mathrm{~S}$ rRNA divergent domains D1 and D8. J Mol Evol 32, 53-63.

Levine, N. D. (1978). Perkinsus gen. n. and other new taxa in the protozoan phylum Apicomplexa. J Parasitol 64, 549.

Levine, N. D. (1985). Phylum Apicomplexa Levine 1970. In An Illustrated Guide to the Protozoa, pp. 322-374. Edited by J. J. Lee, S. H. Hutner \& E. C. Bovee. Lawrence, KS: Society of Protozoologists.

López-García, P., Rodríguez-Valera, F., Pedrós-Alió, C. \& Moreira, D. (2001). Unexpected diversity of small eukaryotes in deep-sea Antarctic plankton. Nature 409, 603-607.

Maruyama, K. \& Sugano, S. (1994). Oligo-capping: a simple method to replace the cap structure of eukaryotic mRNAs with oligoribonucleotides. Gene 138, 171-174.

Moon-van der Staay, S. Y., De Wachter, R. \& Vaulot, D. (2001). Oceanic $18 \mathrm{~S}$ rDNA sequences from picoplankton reveal unsuspected eukaryotic diversity. Nature 409, 607-610.

Norén, F., Moestrup, Ø. \& Rehnstam-Holm, A.-S. (1999). Parvilucifera infectans Norén et Moestrup gen. et sp. nov. (Perkinsozoa phylum nov.): a parasitic flagellate capable of killing toxic microalgae. Eur J Protistol 35, 233-254. 
Perkins, F. O. (1976). Zoospores of the oyster pathogen, Dermocystidium marinum. I. Fine structure of the conoid and other aporozoan-like organelles. J Parasitol 20, 959-974.

Perkins, F. O. (1996). The structure of Perkinsus marinus (Mackin, Owen and Collier, 1950) Levine, 1978 with comments on taxonomy and phylogeny of Perkinsus spp. J Shellfish Res 15, 67-87.

Popovský, J. \& Pfiester, L. A. (1990). Dinophyceae (Dinoflagellida). Süßwasserflora von Mitteleuropa, Band 6. Stuttgart \& Jena: Gustav Fischer.

Reece, K. S., Siddall, M. E., Burreson, E. M. \& Graves, J. E. (1997). Phylogenetic analysis of Perkinsus based on actin gene sequences. J Parasitol 83, 417-423.

Ris, H. \& Kubai, D. F. (1974). An unusual mitotic mechanism in the parasitic protozoan Syndinium sp. J Cell Biol 60, 702-720.

Roberts, K. R. (1985). The flagellar apparatus of Oxyrrhis marina Pyrrophyta. J Phycol 21, 641-655.

Roberts, K. R. (1991). The flagellar apparatus and cytoskeleton of dinoflagellates: organization and use in systematics. In The Biology of Free-Living Heterotrophic Flagellates, pp. 285-302. Systematics Association Special Volume 45. Edited by D. J. Patterson \& J. Larsen. Oxford: Clarendon Press.

Sala-Rovira, M., Geraud, M. L., Caput, D., Jacques, F., SoyerGobillard, M. O., Vernet, G. \& Herzog, M. (1991). Molecular cloning and immunolocalization of two variants of the major basic nuclear protein (HCc) from the histone-less eukaryote Crypthecodinium cohnii (Pyrrhophyta). Chromosoma 100, 510-518.

Saldarriaga, J. F., Taylor, F. J. R., Keeling, P. J. \& Cavalier-Smith, T. (2001). Dinoflagellate nuclear SSU rRNA phylogeny suggests multiple plastid losses and replacements. J Mol Evol 53, 204-213.

Saunders, G. W., Hill, D. R. A., Sexton, J. P. \& Andersen, R. A. (1997). Small-subunit ribosomal RNA sequences from selected dinoflagellates: testing classical evolutionary hypotheses with molecular systematic methods. In Origins of Algae and their Plastids (Plant Systematics and Evolution Supplement), pp. 237-259. Edited by D. Bhattacharya. Vienna: Springer Verlag.

Siddall, M. E., Reece, K. S., Graves, J. E. \& Burreson, E. M. (1997). 'Total evidence' refutes the inclusion of Perkinsus species in the phylum Apicomplexa. Parasitology 115, 165-176.

Siddall, M. E., Reece, K. S., Nerad, T. A. \& Burreson, E. M. (2001). Molecular determination of the phylogenetic position of a species in the genus Colpodella (Alveolata). Am Mus Novit 3314, 1-10.

Simpson, A. G. B. \& Patterson, D. J. (1996). Ultrastructure and identification of the predatory flagellate Colpodella pugnax Cienkowski (Apicomplexa) with a description of Colpodella turpis n. sp. and a review of the genus. Syst Parasitol 33, 187-198.

Sournia, A. (1986). Atlas du Phytoplankton Marin, vol. I, Introduction, Cyanophycees, Dictyochophycees, Dinophycees et Raphidophycees. Paris: Editions du Centre National de la Recherche Scientifique.

Strimmer, K. \& Von Haeseler, A. (1996). Quartet puzzling: a quartet maximum-likelihood method for reconstructing tree topologies. Mol Biol Evol 13, 964-969.

Suzuki, Y., Yoshitomo-Nakagawa, K., Maruyama, K., Suyama, A. \& Sugano, S. (1997). Construction and characterization of a full length-enriched and a 5' -end-enriched cDNA library. Gene 200, 149-156.

Swofford, D. L. (1999). Phylogenetic Analysis using Parsimony (and other Methods). PAUP* 4.0 (test version). Sunderland, MA: Sinauer.

Triemer, R. E. (1982). A unique mitotic variation in the marine dinoflagellate Oxyrrhis marina Pyrrophyta. J Phycol 18, 399-411.

Van de Peer, Y., Caers, A., De Rijk, P. \& De Wachter, R. (1998). Database on the structure of small ribosomal subunit RNA. Nucleic Acids Res 26, 179-182. 